\title{
A rare case of pregnancy in the rudimentary horn of unicornuate uterus (on table diagnosis): a case report
}

\author{
Suman Kumari*, Pratiksha Gupta, Jyoti, Pooja Sharma
}

Department of Obstetrics and Gynecology, ESI-PGIMSR, Basaidarapur, New Delhi, India

Received: 22 January 2019

Accepted: 29 January 2019

*Correspondence:

Dr. Suman Kumari,

E-mail: sumanmishi@gmail.com

Copyright: (C) the author(s), publisher and licensee Medip Academy. This is an open-access article distributed under the terms of the Creative Commons Attribution Non-Commercial License, which permits unrestricted non-commercial use, distribution, and reproduction in any medium, provided the original work is properly cited.

\begin{abstract}
A rudimentary horn with a unicornuate uterus results due to failure of the complete development of one of the Mullerian ducts and incomplete fusion with the contralateral side. Pregnancy in non-communicating rudimentary horn of unicornuate uterus is a rare form of ectopic gestation and it carries grave consequences for mother and the fetus. The most dreaded complication is rupture during pregnancy which can be life threatening to the mother. The continuation of pregnancy is rare till 3rd trimester and usually ruptures in $2^{\text {nd }}$ trimester. The primary strategy of the management is surgical excision of the rudimentary horn. Here is a case of 24year old, gravida1 with unruptured rudimentary horn pregnancy at gestational age 28 weeks diagnosed on table. IOL (induction of labour) was done with misoprostol for fetal demise and later cesarean section done in view of failed induction. Laparotomy was done and dead fetus with placenta delivered followed by excision of the rudimentary horn. The post-operative period was uneventful. This highlights the need of an increased awareness of this condition especially in developing countries where most pregnancy are unbooked and uninvestigated as in present case.
\end{abstract}

Keywords: Cesarean section, Ectopic gestation, Rudimentary horn, Unicornuate uterus

\section{INTRODUCTION}

Mullerian anomalies were first classified in 1979 by Buttram and Gibbons and further revised by the American Society of Reproductive Medicine (ASRM) in 1988. According to ASRM, unicornuate uterus is a type 2 classification with unilateral hypoplasia or agenesis that can be further sub-classified into communicating, noncommunicating, no cavity, and no horn. ${ }^{1}$ Latest classification of Mullerian anomalies by ESHRE-ESGE (Grimbizis et al) classify unicornuate uterus to Class $\mathrm{U} 4 \mathrm{a} / \mathrm{Hemi}$ uterus with a rudimentary (functional) cavity. ${ }^{2}$ The incidence of uterine congenital anomalies because of Mullerian defects in the normal fertile population is $3.2 \%$. An unicornuate uterus accounts for $2.4 \%-13 \%$ of all Mullerian anomalies. ${ }^{3} 72-85 \%$ of the rudimentary horns are non-communicating with the cavity. ${ }^{4}$
Unicornuate uterus with rudimentary horn may be associated with gynecological and obstetric complications like infertility, endometriosis, hematometra, urinary tract anomalies, abortions and preterm deliveries. The most dreaded complication is rupture during pregnancy which can be life threatening to the mother. Authors report a case of unruptured rudimentary horn pregnancy at 28 weeks of gestation misdiagnosed as intrauterine pregnancy and attempted termination for fetal demise.

\section{CASE REPORT}

The 24-year-old, gravida 1 was admitted in labour room of gynae causality at ESI hospital, Basaidarapur with diagnosis of IUFD (intrauterine fetal demise) for induction of labour. There was one USG report from 
private stating intrauterine fetal demise (IUFD) of 28 weeks but there were no any other investigation with her. She was unbooked and uninvestigated. At presentation, she looked well with PR of $88 \mathrm{bpm}$ and $\mathrm{BP}$ of $120 / 80 \mathrm{mmHg}$. Her height was $152 \mathrm{~cm}$ and her weight was $55 \mathrm{~kg}$. Her uterine fundal height corresponded to $26-28$ weeks size. There was no history of bleeding or leaking per vaginum. Her $\mathrm{Hb}$ was $9 \mathrm{gm} / \mathrm{dl}$ and her RBS was $98 \mathrm{mg} / \mathrm{dl}$. Induction of labour (IOL) was done by 50 microgram tablet misoprostol followed by repeat dose at 6-hour interval.

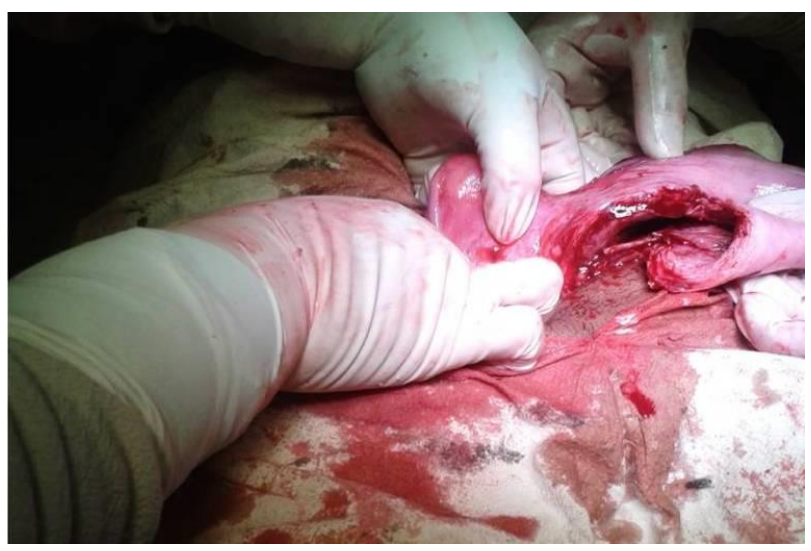

Figure 1: Intraoperative photograph showing anterior view of the uterus with the rudimentary horn attached to its left border and incision given on anterior surface to deliver the dead fetus with the placenta.

Based on two failed attempts for IOL, she was counseled and prepared for cesarean section and laparotomy was done and dead fetus with the placenta delivered followed by excision of rudimentary horn. The findings of surgery were: normal/slightly bulky uterus, pregnancy in left rudimentary horn of the uterus which was attached with the body of the uterus, the cavity of the horn did not communicate with the uterine cavity.

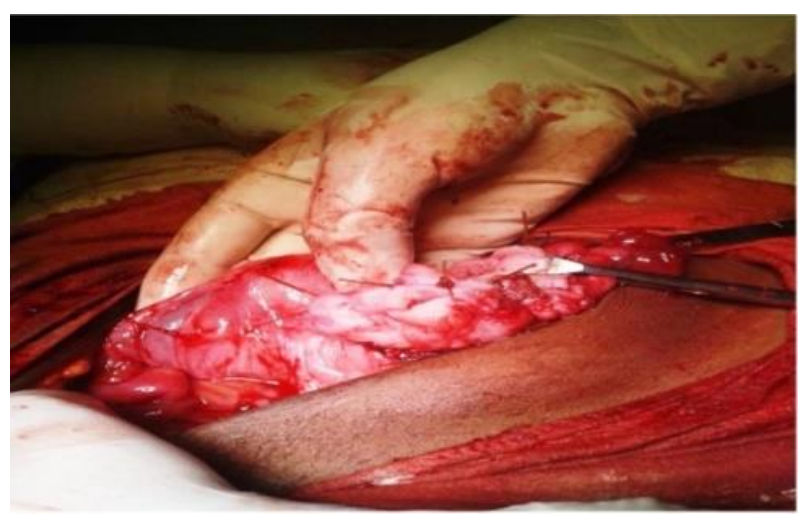

Figure 2: Intraoperative photograph after excision of the rudimentary horn with repair and, right tube and ovary intact.

The left fallopian tube was of normal length and it was attached to the rudimentary horn. The left ovary was normal, and it was attached by its ligament to rudimentary horn. The right tube and right ovary were normal. The fetus with the placenta was taken out by incision on the anterior surface of rudimentary horn followed by excision of rudimentary horn and the left tube. KUB region was palpated to detect any abnormality. Her post-operative recovery was normal, and she was discharged on $8^{\text {th }}$ postoperative day.

\section{DISCUSSION}

A rudimentary horn with a unicornuate uterus results due to failure of the complete development of one of the Mullerian ducts and incomplete fusion with the contralateral side. The incidence is estimated at 1 per 100,000 to 140,000 pregnancies. $^{3}$ Pregnancy in a noncommunicating rudimentary horn occurs through the trans- peritoneal migration of the spermatozoon or the fertilized ovum. ${ }^{5}$ The timing of rupture varies from 5 to 35 weeks depending on the horn musculature and its ability to hypertrophy and dilate. $70-90 \%$ rupture occurs before 20 weeks and can be catastrophic. ${ }^{6}$ As the uterine wall is thicker and more vascular, bleeding is more severe in rudimentary horn pregnancy rupture. ${ }^{7}$ The diagnostic tools are ultrasound, hysterosalpingogram, hysteroscopy, laparoscopy, and MRI. ${ }^{8}$ Fedele et al have found ultrasonography to be useful in the diagnosis. ${ }^{9}$ But the sensitivity of ultrasound is only $26 \%$ and sensitivity decreases as the pregnancy advances. ${ }^{10}$

Tubal pregnancy, cornual pregnancy, intrauterine pregnancy, and abdominal pregnancy are common sonographic misdiagnosis. ${ }^{11}$ Tsafrir et al outlined a set of criteria for diagnosing pregnancy in the rudimentary horn. ${ }^{12}$ They are a pseudo pattern of asymmetrical bicornuate uterus; absent visual continuity of tissue surrounding the gestation sac and the uterine cervix; presence of myometrial tissue surrounding the gestational sac. Samuels and Awonuga reported rupture after use of misoprostol due to misdiagnosis. ${ }^{13}$ Non-responders to induced abortion should be investigated with a high index of suspicion. Primary strategy of management of rudimentary horn is surgical removal. ${ }^{14}$ There are instances of early diagnosis and laproscopic excision of rudimentary horns. Medical management with methotrexate and its resection by laproscopy is also reported. Edelman et al. showed a case detected at an early gestational week and treated successfully with methotrexate administration. ${ }^{15}$ Immediate surgery is recommended by most after the diagnosis, even in unruptured cases. ${ }^{10}$ Removal of the horn prior to pregnancy in order to prevent complications is also advised. However, conservative management until viability is achieved, has been advocated in few selected cases if emergency surgery can be performed anytime and if the patient is well informed. ${ }^{14} \mathrm{~A}$ case of pregnancy progressing to the third trimester and resulting in livebirth after cesarean section has been documented. ${ }^{16}$ Renal anomalies are found in $36 \%$ of cases; hence it is mandatory to further assess these women. ${ }^{10}$ 


\section{CONCLUSION}

Despite advances in ultrasound and other diagnostic modalities, prenatal diagnosis remains elusive, with confirmatory diagnosis being laparotomy. There is a need for an increased awareness of this condition especially in developing countries where most pregnancy are unbooked and uninvestigated. High index of suspicion should be kept in teenagers presenting with dysmenorrhea. Pregnancy in rudimentary horn is very rare but it can be life threatening. A careful pelvic examination in the $1^{\text {st }}$ trimester showing deviated uterus with palpable contralateral pelvic adnexa should arise suspicion of uterine anomaly as both clinically and radio logically, the diagnosis is more accurate in first trimester.

Funding: No funding sources

Conflict of interest: None declared

Ethical approval: Not required

\section{REFERENCES}

1. Hassan CH, Karim AK, Ismail NA, Omar MH. Case report of ruptured non-communicating right rudimentary horn pregnancy: an acute emergency. Acta Medica. 2011;54(3):125-6.

2. Grimbizis GF, Campo R. Congenital malformations of the female genital tract: the need for a new classification system. Fertil Steril. 2010;94(2):401-7.

3. Simón C, Martinez L, Pardo F, Tortajada M, Pellicer A. Müllerian defects in women with normal reproductive outcome. Fertil Steril. 1991;56(6):11923.

4. Sevtap HK, Aral AM, Sertac B. An early diagnosis and successful local medical treatment of a rudimentary uterine horn pregnancy: a case report. Arch Gynecol Obstet. 2007;275(4):297-8.

5. Scholtz M. A full-time pregnancy in a rudimentary horn of the uterus. BJOG: An Int J Obstet Gynaecol. 1951;58(2):293-6.

6. O'leary JL, O'leary JA. Rudimentary horn pregnancy. Obstet Gynecol. 1963;22(3):371-5.

7. Chowdhury S, Chowdhury T, Azim E. Pregnancy in a non-communicating rudimentary horn of uterus: a clinical case report. Bangla Med J. 2010;39(1):47-8.
8. Lawhon BP, Wax JR, Dufort RT. Rudimentary uterine horn pregnancy diagnosed with magnetic resonance imaging. Obstet Gynecol. 1998;91(5):869.

9. Fedele L, Dorta M, Vercellini P, Brioschi D, Candiani GB. Ultrasound in the diagnosis of subclasses of unicornuate uterus. Obstet Gynecol. 1988;71(2):274-7.

10. Jayasinghe Y, Rane A, Stalewski H, Grover S. The presentation and early diagnosis of the rudimentary uterine horn. Obstet Gynecol. 2005;105(6):1456-67.

11. Bahadori F, Borna S, Behroozlak T, Hoseini S, Ayatollahi H. Failed induction in second trimester due to pregnancy in an uncommunicated rudimentary horn: case report. J Fam Reprod Health. 2009;3(3):95-7.

12. Tsafrir A, Rojansky N, Sela HY, Gomori JM, Nadjari M. Rudimentary horn pregnancy: Firsttrimester prerupture sonographic diagnosis and confirmation by magnetic resonance imaging. J Ultrasound Med. 2005;24(2):219-23.

13. Samuels TA, Awonuga A. Second-trimester rudimentary uterine horn pregnancy: rupture after labor induction with misoprostol. Obstet Gynecol. 2005;106(5):1160-2.

14. Nahum GG. Rudimentary uterine horn pregnancy. The 20th-century worldwide experience of 588 cases. J Reprod Med. 2002;47(2):151-63.

15. Edelman AB, Jensen JT, Lee DM, Nichols MD. Successful medical abortion of a pregnancy within a noncommunicating rudimentary uterine horn. Am J Obstet Gynecol. 2003;189(3):886-7.

16. Shin JW, Kim HJ. Case of live birth in a noncommunicating rudimentary horn pregnancy. J Obstet Gynaecol Res. 2005;31(4):329-31.

Cite this article as: Kumari S, Gupta P, Jyoti, Sharma P. A rare case of pregnancy in the rudimentary horn of unicornuate uterus (on table diagnosis): a case report. Int J Reprod Contracept Obstet Gynecol 2019;8:1190-2. 